\title{
RESEARCH PAPER \\ PREVALENCE OF PARASITAEMIA, ANAEMIA AND TREATMENT OUTCOMES OF MALARIA AMONG SCHOOL CHILDREN IN A RURAL COMMUNITY IN GHANA
}

\author{
E. Otupiri ${ }^{1}$, D. Yar ${ }^{1,2}$, and M. J. Hindin ${ }^{2}$ \\ ${ }^{I}$ Department of Community Health, School of Medical Sciences, KNUST, Kumasi \\ easmono@yahoo.com \\ ${ }^{2}$ Johns Hopkins Bloomberg School of Public Health, Dept. of Population Family and Reproductive \\ Health, USA
}

\begin{abstract}
A cross-sectional survey was conducted in the Ejisu-Juaben District to determine the prevalence of asymptomatic malaria and anaemia, and treatment outcomes in pupils of seven public schools public schools in a rural community in the forest belt of Ghana. Children with confirmed malaria parasites were randomly assigned to be treated with Artemisinin-based combination therapies available on the Ghanaian market. Post-treatment days 14 and 28 follow-up blood samples were taken to determine the treatment outcomes on peripheral parasitaemia and haemoglobin (Hb) concentrations. Out of 812 pupils (without malaria symptoms) who were screened, the baseline parasitaemia prevalence was 58.6\%. Parasitaemia prevalence across the seven (7) public schools ranged from $49.7 \%$ to $71.0 \%(p=0.002)$. Post-treatment parasitaemia among the different treatment regimes were significant only at day 28 (p<0.001). The mean Hb concentration on the screening day was $10.5 \mathrm{~g} / \mathrm{dl}$ and over $60 \%$ of pupils were mildly anaemic $(\mathrm{Hb}<11.0 \mathrm{~g} / \mathrm{dl})$ whereas $14 \%$ had $\mathrm{Hb}<8.0 \mathrm{~g} / \mathrm{dl}$. Post-treatment $\mathrm{Hb}$ concentrations of pupils by days 14 and 28 were $11.4 \mathrm{~g} / \mathrm{dl}$ and $11.7 \mathrm{~g} / \mathrm{dl}$ with an improvement of $0.7 \mathrm{~g} / \mathrm{dl}$ and $0.9 \mathrm{~g} / \mathrm{dl}$ respectively over the baseline $\mathrm{Hb}$ concentration $(\mathrm{p}<0.001)$. The overall proportion of children with $\mathrm{Hb}$ concentrations $<11.0 \mathrm{~g} / \mathrm{dl}$ was $32.6 \%$ and $25.3 \%$ by days 14 and 28 respectively. The burden of malaria and anaemia among school children is high and warrants investment to reduce these levels. These findings could be a reflection of the health situation that pertains in the basic public schools especially in the rural forest areas of Ghana.
\end{abstract}

Keywords: asymptomatic malaria, parasitaemia, anaemia, pupils, rural Ghana

\section{INTRODUCTION}

Malaria episodes among African children are estimated to be between 1.6 and 5.4 million each year. This varies according to geographical and epidemiological circumstances (Murphy et al., 2001). Research has shown that about $75 \%$ of the total number of deaths of children as a result of malaria is recorded in Africa (RBM, 2002; WHO, 2003; UNICEF, 2006). The disease contributes greatly to anaemia and accounts for about one-in-five of all childhood deaths (UNICEF, 2004). In malariaendemic areas, a significant proportion of children harbour parasites without presenting signs 


\section{Otupiri et al.}

of clinical malaria and are considered asymptomatic cases (Greenwood, 1987; Landry-Erik et al., 2003). Asymptomatic malaria can affect the individuals who carry the parasites and are cryptic carrier reservoirs for the community (Osorio et al., 2004; Ashton et al., 2011).

School children are often thought of as naturally healthy as long as they turn up at school. However, studies have shown that in Africa, more than half of the school children are stunted in height and are anaemic (WHO, 1997; Partnership for Child Development, 1998). In many areas, most school children are infected with worms, Schistosoma and malaria parasites. These highly prevalent conditions are all associated with impaired cognitive ability (Fernando et al., 2003). Ensuring good health when children are of school-going age can boost attendance and educational achievement (Snow et al., 1999). The impact of repeated malaria episodes on the development of the child, particularly as they relate to mental and cognitive function, could be relevant to the later potential and prosperity of the individual and the community (Siâne et al., 1998; Siâne et al., 2004). Little is known about malaria among school children despite the potential impact malaria can have on school performance and educational attainment (Holding et al., 1999; Holding and Snow, 2001; Fernando et al., 2003).

Although nutritional deficiencies, hookworm infection, HIV and haemoglobinopathies all predispose to the development of anaemia in children, evidence suggests that, in endemic countries, malaria is one of the most important factors (Murphy and Breman, 2001). Individuals chronically infected with malaria parasites are usually unidentifiable by most malaria control programmes (Osorio et al., 2004). Schools however, can offer a potential delivery mechanism for interventions but data are lacking to determine whether or not the burden of malaria among school children is sufficient to warrant investment (Bundy et al., 2000).
This study sought to determine the prevalence of parasitaemia and anaemia among school children in pre- and primary schools and to assess the effect of different Artemisininsbased combination therapies (ACTs) on the haemoglobin $(\mathrm{Hb})$ levels of infected individuals by days 14 and 28 post-treatment follow-up.

\section{MATERIALS AND METHODS Study Area}

The study was carried out in the Ejisu-Juaben municipality which is one of the 27 districts and municipalities of the Ashanti Region, Ghana. Its population in the year 2004 was projected at 145,626 with a growth rate of $2.7 \%$. The population aged below one year is $4 \%$ and pre-school children constituted $20 \%$ of the population. The climate is tropical: temperature variation is $20^{\circ} \mathrm{C}-36^{\circ} \mathrm{C}$ with monthly rainfall varying from $2.0 \mathrm{~mm}$ in February to $400 \mathrm{~mm}$ in July. It is a predominantly rural district, with the main occupation of the people being subsistence farming. Malaria is the leading cause of outpatient department (OPD) visits (44.3\%). Malaria is hyper-endemic (Browne et al., 2000) and accounts for $42.9 \%$ of the total admissions of the top-five diseases in the district (Ghana Health Service/Ejisu-Juaben Municipal Health Management Team, 2003). There is little seasonal variation in malaria transmission, parasite rates being slightly higher during the rainy season.

\section{Methods}

The study population comprised of pre-school and primary school children aged 3 to 10 years, head teachers, opinion leaders and mothers or caregivers of pupils resident in seven farming communities. The municipality has five (5) sub -districts: Achiase, Bomfa, Ejisu, Juaben and Kwaso. Simple random sampling was used to select two sub-districts - Juaben and Bomfa. These two (2) sub-districts have a total of 54 communities out of which 37 are rural farming communities while the rest have peri-urban and urban characteristics. Seven (7) rural farming communities: Abesewase, Abetinim, Atia, Nkyerepoaso, Odoyefe, Ofoase, and Nobewam 
were randomly selected for the study. Each of these communities had one public school. All the pupils (920) in these schools who were aged 3-10 years were screened and 898 were found to be eligible for the study; the children were without chronic or severe diseases such as anaemia and sickle cell disease or not on medication for these diseases.

Two data collection sessions were undertaken: from January to March, 2006 and from May to August, 2006 coinciding with the dry and wet seasons respectively. A total of 82 eligible pupils were enrolled after their parents/caregivers consented to their participation in the study, and their weights and temperatures were recorded; 86 parents/caregivers did not consent to their children's participation. Finger-pricked blood samples were used to prepare thick and thin blood films. These blood films were stained with $3 \%$ Giemsa-stain for 30 minutes and examined microscopically using the X100 objective. A slide was declared negative after examining 200 high power fields. Each thick blood smear was read by two different highly qualified slide readers, and parasitaemia was quantified against 200 white blood cells.

Thick blood smears were read twice and parasitaemia quantified against 200 white blood cells. An assumption of 8000 leucocytes per microlitre of blood was used to calculate the parasite density. Discrepant slides were read again by a third slide reader and the majority opinion taken. All the pupils with parasitaemia were randomly treated with various ACTs available on the Ghanaian market. Their haemoglobin concentrations were determined to an accuracy of $1 \mathrm{~g} / \mathrm{dl}$ with the HemoCue haemoglobinometer (HemoCue AB, Angelholm, Sweden) using capillary blood samples drawn at days 0,14 and 28 . We recorded the post-treatment haemoglobin and parasitaemia levels of the same pupils at days 14 and 28 follow-up.

Ethical clearance was obtained from the School of Medical Sciences-Komfo Anokye Teaching Hospital Committee on Human Research, Pub- lications and Ethics (CHRPE) and the Ghana Health Service Ethical Review Committee on Research Involving Human Subjects (ERCRIHS). Administrative clearance was obtained from the district directorates of the Ghana Health Service and Ghana Education Service respectively. Community chiefs and leaders also gave their approval for the study. Verbal consent was obtained from the mothers or caregivers of eligible children before they were enrolled into the study. All information collected was treated confidentially and used for research purposes only.

\section{Statistical analyses}

Data were double-entered using EPI-Info version 3.3.2 (CDC, Atlanta; WHO Geneva) and statistical analysis was conducted using STATA version 9.1 (Stata Corp., College Station, Texas: StataCorp LP, USA). Descriptive statistics was used to summarize and display the data in tables and graphs. The effect of treatment with ACTs on $\mathrm{Hb}$ outcome was assessed by determining the absolute change from the baseline $\mathrm{Hb}$ (day 0) and, days 14 and 28 using One-way Analysis of Variance (ANOVA) and t-test for group data. The mean $\mathrm{Hb}$ concentration of each treatment group was compared with $\mathrm{Hb}$ concentration for the treatment group that received ArtesunateAmodiaquine (ART+AMQ) which is the standard treatment option in Ghana for uncomplicated malaria. For continuous variables, the estimates were for differences in means at $95 \%$ confidence interval.

\section{RESULTS AND DISCUSSION}

The results are based on the analyses of daa from 812 school pupils drawn from the seven (7) public schools. The same pupils examined at day 0 (baseline), were examined again at days 14 and 28 post-treatement. Of the the total of 812 school pupils screened for malaria parasites, $476(58.6 \%)$ wee positive; less tha $1 \%$ of the slides needed to be read by a third slid reader. Out of these 476 who were positive at day 0 and were treated with ACTs, 398 (83.8\%) were available for $\mathrm{Hb}$ concentration assessment 
at day 14 (loss of $16.2 \%$ to follow-up between days 0 and 14), while 390 (81.9\%) were available for the same assessment at day 28 (loss of $18.1 \%$ to follow-up between days 0 and 28 , and $2.3 \%$ between days 14 and 28 ).

\section{Parasitaemia prevalence}

The overall parasetaemia prevalence in the study sample was $59 \%$ and among those with parasitaemia, it was significantly higher in the wet season compared with the dry season $(=0.0001)$. The parasitaemia prevalence varied from community to community ranging from $49.7 \%$ in Abetenim to $71 \%$ in Nkyerepoase $(\mathrm{p}=0.002)$. Species of Plasmodium detected were: falciparum (97.4\%), malariae (1.6\%) and ovale $(1 \%)$ with a gametocyte rate of $5.3 \%$. The mean age of pupils was 7.3 years $(\mathrm{SD} \pm 3.14)$ with a range of 3-10 years. Parasitaemia varied only slightly $(\mathrm{p}=0.6)$ among the different age groups (data not shown).

\section{Baseline weights, haematological indices and} temperatures of pupils (day 0 )

The baseline weights of the children screened ranged from $11.0 \mathrm{~kg}$ to $35.0 \mathrm{~kg}$ with a mean of $18.3 \mathrm{~kg}(\mathrm{SD} \pm 3.7)$. The haemoglobin $(\mathrm{Hb})$ concentrations ranged from $7.1 \mathrm{~g} / \mathrm{dl}$ to $14.6 \mathrm{~g} / \mathrm{dl}$ with a mean of $10.8 \mathrm{~g} / \mathrm{dl}(\mathrm{SD} \pm 1.2)$. The Hb concentrations of pupils with peripheral parasitaemia ranged from $7.1 \mathrm{~g} / \mathrm{dl}$ to $14.0 \mathrm{~g} / \mathrm{dl}$ with a mean of $10.8 \mathrm{~g} / \mathrm{dl}(\mathrm{SD} \pm 1.2)$ whereas those without the parasites had $\mathrm{Hb}$ concentrations ranging from $8.0 \mathrm{~g} / \mathrm{dl}$ to $14.6 \mathrm{~g} / \mathrm{dl}$ with a mean of $11.1 \mathrm{~g} / \mathrm{dl}$ (SD \pm 1.2 ). Over $60 \%$ of the pupils screened were anaemic $(\mathrm{Hb}<11.0 \mathrm{~g} / \mathrm{dl})$ of which $14 \%$ had $\mathrm{Hb}$ $<8.0 \mathrm{~g} / \mathrm{dl}$. Body temperatures of pupils ranged from $34.5^{\circ} \mathrm{C}$ to $39.5^{\circ} \mathrm{C}$ with a mean of $36.5^{\circ} \mathrm{C}$ ( $\mathrm{SD} \pm 0.6$ ). The baseline (day 0 ) body weights, temperatures and haematological indices among the study communities varied only marginally (Table 1).

\section{Parasitological outcomes after initial treat- ment with ACTs in pupils}

The incidence of parasitaemia at days 14 and 28 after treatment with ACTs are summarized in Fig. 1. The failure was higher at day 28 $(n=390)$ compared with day 14, except for Amotex ${ }^{\circledR}$. This suggests that, when compared with the other ACTs used in the study, Amotex $®$ may be more effective in clearing malaria parasites.

\section{Haematological outcomes after initial treat- ment with ACTs in pupils}

In Table 2, by day 14, the overall proportion of children with haemoglobin $(\mathrm{Hb})$ concentrations between 8.0 to $10.9 \mathrm{~g} / \mathrm{dl}$ was $32.6 \%$ whereas children with $\mathrm{Hb}$ concentrations $\geq 11.0 \mathrm{~g} / \mathrm{dl}$ was $67.4 \%$ with an overall mean $\mathrm{Hb}$ concentration of $11.5 \mathrm{~g} / \mathrm{dl}$. Within the treatment groups, the proportion of children with $\mathrm{Hb}$ concentrations between 8.0 to $10.9 \mathrm{~g} / \mathrm{dl}$ ranged from $26.8 \%$ to $37.5 \%$ with mean $\mathrm{Hb}$ concentrations ranging from 11.3 to $11.7 \mathrm{~g} / \mathrm{dl}$.

By day 28, the overall proportion of children with haemoglobin $(\mathrm{Hb})$ concentrations between 8.0 to $10.9 \mathrm{~g} / \mathrm{dl}$ was $25.3 \%$ whereas children with $\mathrm{Hb}$ concentrations $\geq 11.0 \mathrm{~g} / \mathrm{dl}$ was $74.7 \%$ with an overall mean $\mathrm{Hb}$ concentration of $11.7 \mathrm{~g} / \mathrm{dl}$, an insignificant increase of $0.2 \mathrm{~g} / \mathrm{dl}$ over the day 14 mean $\mathrm{Hb}(\mathrm{p}=0.4)$. Within the treatment groups, the proportion of children with $\mathrm{Hb}$ concentrations between 8.0 to $10.9 \mathrm{~g} / \mathrm{dl}$ ranged from minimum of $21.4 \%$ to a maximum of $30.8 \%$ with mean $\mathrm{Hb}$ concentrations ranging from 11.5 to $12.0 \mathrm{~g} / \mathrm{dl}$. (Table 3 )

The change in mean $\mathrm{Hb}$ concentrations by days 14 and 28 within the treatment groups were compared as shown in Table 4. Many of the treatments showed significant increases in mean $\mathrm{Hb}$ levels between days 0 and 14 (ART/ AMQ, ART/CQ, ART/LAPDAP, and Coartem®) but only two (ART/AMQ and Coartem®) showed statistically significant differences in mean $\mathrm{Hb}$ levels between days 0 and 14 , and days 0 and 28 respectively.

The antimalarials used in the study were available on the Ghanaian market and were manufactured by: MAPHAR of Morocco Arsucam $\left.{ }^{\circledR}\right)$,Wufung Pharma of Germany (Lapdap $^{\mathrm{TM}}$ ), F. Hoffmann-La Roche of Switzer- 
Table 1: Baseline body weight, temperature and haematological indices of pupils $(n=812)$

\begin{tabular}{llllllll}
\hline Variable & Total & $\begin{array}{l}\text { Mean Wgt } \\
(\mathbf{K g})\end{array}$ & SD \pm & $\begin{array}{l}\text { Mean Hb } \\
(\mathbf{g} / \mathbf{d l})\end{array}$ & SD \pm & $\begin{array}{l}\text { Mean } \\
\text { Temp }\left({ }^{\circ} \mathbf{C}\right)\end{array}$ & SD \pm \\
\hline Abetenim & 144 & 19.5 & 3.9 & 11.0 & 1.1 & 36.5 & 0.5 \\
Atia & 161 & 17.3 & 2.5 & 10.2 & 1.0 & 36.4 & 0.9 \\
Ofoase & 173 & 18.5 & 4.0 & 11.3 & 1.5 & 36.5 & 0.8 \\
Abesewase & 52 & 16.4 & 3.5 & 10.6 & 1.3 & 36.6 & 0.9 \\
Nkyerepoase & 172 & 19.8 & 3.7 & 10.9 & 1.0 & 36.4 & 0.7 \\
Nobewam & 92 & 17.0 & 2.3 & 10.7 & 1.4 & 36.6 & 1.1 \\
Odoyefe & 18 & 18.7 & 2.3 & 10.1 & 1.6 & 36.6 & 0.9 \\
\hline Wgt=weight & & & & & & &
\end{tabular}

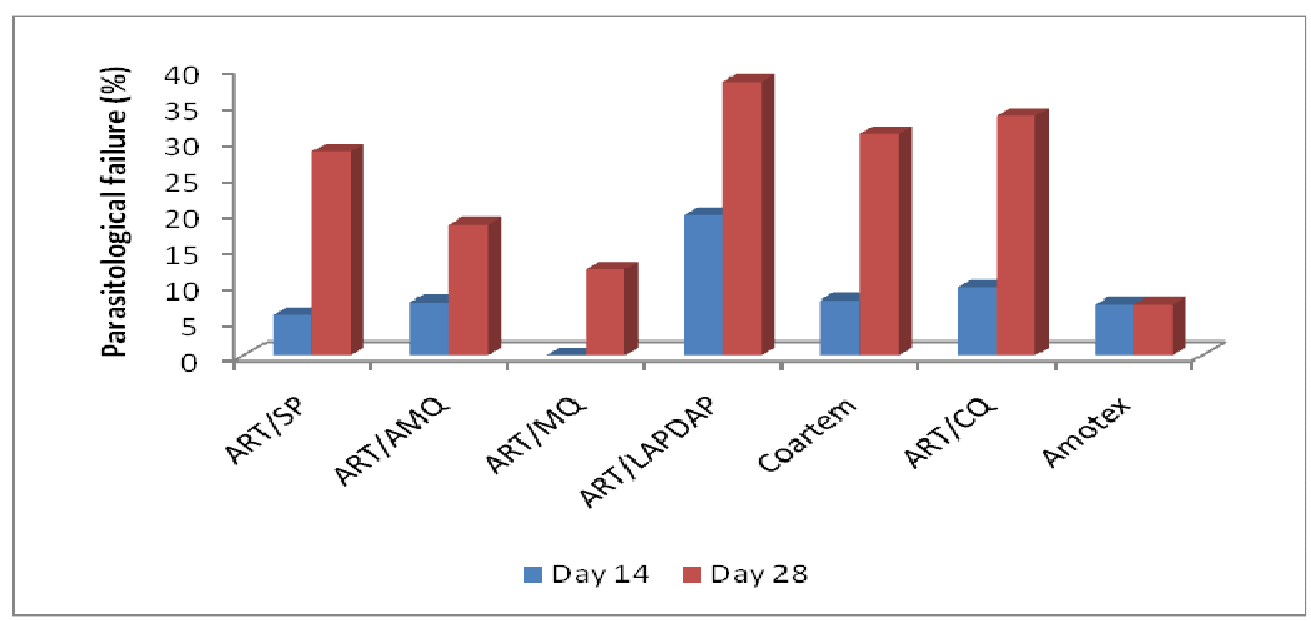

Fig.1: Crude parasitological failures of ACTs at days 14 and 28

Table 2: Haemoglobin concentrations at day 14 post-treatment $(\mathrm{N}=399)$

\begin{tabular}{llllllllll}
\hline HB $(\mathbf{g} / \mathbf{d l})$ & $\mathbf{8 - 1 0 . 9}$ & \multicolumn{2}{c}{$\geq \mathbf{1 1}$} & Mean & SD \pm & Min & Max & Total \\
Day 14 & $\mathbf{n}$ & $\mathbf{\%}$ & $\mathbf{n}$ & $\mathbf{\%}$ & & & & & \\
\hline ART/SP & 23 & 31.9 & 49 & 68.1 & 11.5 & 1.1 & 8.9 & 13.5 & $\mathbf{7 2}$ \\
ART/AMQ & 28 & 34.6 & 52 & 65.4 & 11.4 & 1.2 & 8.7 & 15.6 & $\mathbf{8 1}$ \\
ART/MQ & 7 & 26.9 & 19 & 73.1 & 11.6 & 1.2 & 9.4 & 13.9 & $\mathbf{2 6}$ \\
ART/LAPDAP & 11 & 26.8 & 30 & 73.2 & 11.7 & 1.2 & 8.9 & 14.3 & $\mathbf{4 1}$ \\
Coartem & 12 & 30.8 & 27 & 69.2 & 11.4 & 1.1 & 9.3 & 13.8 & $\mathbf{3 9}$ \\
ART/CQ & 28 & 33.3 & 56 & 66.7 & 11.6 & 1.1 & 8.9 & 14.6 & $\mathbf{8 4}$ \\
Amotex & 21 & 37.5 & 35 & 62.5 & 11.3 & 1.1 & 8.9 & 14.6 & $\mathbf{5 6}$ \\
Total & $\mathbf{1 3 0}$ & $\mathbf{3 2 . 6}$ & $\mathbf{2 6 9}$ & $\mathbf{6 7 . 4}$ & $\mathbf{1 1 . 5}$ & $\mathbf{1 . 2}$ & $\mathbf{8 . 7}$ & $\mathbf{1 5 . 6}$ & $\mathbf{3 9 9}$ \\
\hline
\end{tabular}


Table 3: Haemoglobin concentrations at day 28 post-treatment $(n=390)$

\begin{tabular}{lccccccccc}
\hline HB $(\mathbf{g} / \mathbf{d l})$ & $\mathbf{8 - 1 0 . 9}$ & $\mathbf{2}$ & $\mathbf{1 1}$ & $\mathbf{n}$ & Mean & SD \pm & Min & Max & Total \\
Day 28 & $\mathbf{n}$ & $\mathbf{\%}$ & $\mathbf{n}$ & $\mathbf{\%}$ & & & & & \\
\hline ART/SP & 20 & 29.9 & 47 & 70.1 & 11.5 & 1.0 & 9.5 & 14.6 & $\mathbf{6 7}$ \\
ART/AMQ & 17 & 22.1 & 60 & 77.9 & 11.7 & 1.1 & 8.9 & 14.6 & $\mathbf{7 7}$ \\
ART/MQ & 7 & 28 & 18 & 72 & 11.7 & 1.2 & 9.8 & 14.3 & $\mathbf{2 5}$ \\
ART/LAPDAP & 9 & 21.4 & 33 & 78.6 & 11.8 & 1.1 & 9.6 & 14.7 & $\mathbf{4 2}$ \\
Coartem & 12 & 30.8 & 27 & 69.2 & 11.5 & 1.2 & 8.9 & 13.4 & $\mathbf{3 9}$ \\
ART/CQ & 22 & 26.2 & 62 & 73.8 & 11.7 & 1.0 & 8.8 & 14.2 & $\mathbf{8 4}$ \\
Amotex & 12 & 21.4 & 44 & 78.6 & 12.0 & 1.2 & 9.7 & 15.5 & $\mathbf{5 6}$ \\
Total & $\mathbf{9 9}$ & $\mathbf{2 5 . 3}$ & $\mathbf{2 9 1}$ & $\mathbf{7 4 . 7}$ & $\mathbf{1 1 . 7}$ & $\mathbf{1 . 1}$ & $\mathbf{8 . 8}$ & $\mathbf{1 5 . 5}$ & $\mathbf{3 9 0}$ \\
\hline
\end{tabular}

Table 4: Comparison of mean Hb changes within treatment groups at days 0,14 and 28

\begin{tabular}{|c|c|c|c|c|}
\hline Treatment & $\begin{array}{l}\text { Baseline (Day } \\
\text { 0) Hemoglobin }\end{array}$ & $\begin{array}{c}\text { Day } 14 \\
\text { Hemoglobin }\end{array}$ & $\begin{array}{c}\text { Day } 28 \\
\text { Hemoglobin }\end{array}$ & Paired t-tests \\
\hline $\begin{array}{l}\text { ART/AMQ, mean } \\
\text { (SD) } \\
\mathrm{N}=33 \text { children } \\
\left.\text { (ARSUCAM }{ }^{\circledR}\right)\end{array}$ & $11.15(1.18)$ & $11.68(1.30)$ & $11.57(0.95)$ & $\begin{array}{l}\text { p-value } 0 \text { vs. } 14=0.05 \\
\text { p-value } 0 \text { vs. } 28=0.11 \\
\text { p-value } 14 \text { vs. } 28=0.21\end{array}$ \\
\hline $\begin{array}{l}\text { ART/CQ, mean } \\
\text { (SD) } \\
\text { N=29 Children }\end{array}$ & $10.85(1.47)$ & $11.51(1.13)$ & $11.60(1.14)$ & $\begin{array}{l}\text { p-value } 0 \text { vs. } 14=0.055 \\
\text { p-value } 0 \text { vs. } 28=0.02 \\
\text { p-value } 14 \text { vs. } 28=0.17\end{array}$ \\
\hline $\begin{array}{l}\text { ART/LAPDAPTM } \\
\text { mean }(\mathrm{SD}) \\
\mathrm{N}=18 \text { children }\end{array}$ & $11.13(1.50)$ & $11.95(1.45)$ & $11.66(1.67)$ & $\begin{array}{l}\text { p-value } 0 \text { vs. } 14=0.04 \\
\text { p-value } 0 \text { vs. } 28=0.27 \\
\text { p-value } 14 \text { vs. } 28=0.80\end{array}$ \\
\hline $\begin{array}{l}\text { ART/Lariam } ®, \\
\text { mean }(\mathrm{SD}) \\
\mathrm{N}=11 \text { children }\end{array}$ & $11.07(1.54)$ & $11.35(1.38)$ & $11.29(1.03)$ & $\begin{array}{l}\text { p-value } 0 \text { vs. } 14=0.61 \\
\text { p-value } 0 \text { vs. } 28=0.65 \\
\text { p-value } 14 \text { vs. } 28=0.95\end{array}$ \\
\hline $\begin{array}{l}\text { ART/Malafan }{ }^{\mathrm{TM}} \\
\text { mean }(\mathrm{SD}) \\
\mathrm{N}=29 \text { children }\end{array}$ & $13.93(2.97)$ & $11.81(1.07)$ & $11.21(0.92)$ & $\begin{array}{l}\text { p-value } 0 \text { vs. } 14=0.49 \\
\text { p-value } 0 \text { vs. } 28=0.37 \\
\text { p-value } 14 \text { vs. } 28=0.43\end{array}$ \\
\hline $\begin{array}{l}\text { Amotex } ® \text {, mean } \\
(\mathrm{SD}) \\
\mathrm{N}=29 \text { children }\end{array}$ & $10.86(0.79)$ & 11.32 & $11.97(1.38)$ & $\begin{array}{l}\text { p-value } 0 \text { vs. } 14=0.10 \\
\text { p-value } 0 \text { vs. } 28=0.0003 \\
\text { p-value } 14 \text { vs. } 28=0.001\end{array}$ \\
\hline $\begin{array}{l}\text { Coartem }{ }^{\circledR} \text {, mean } \\
(\mathrm{SD}) \\
\mathrm{N}=21 \text { children }\end{array}$ & $10.73(0.97)$ & $11.63(1.18)$ & $11.31(0.86)$ & $\begin{array}{l}\text { p-value } 0 \text { vs. } 14=0.01 \\
\text { p-value } 0 \text { vs. } 28=0.05 \\
\text { p-value } 14 \text { vs. } 28=0.66\end{array}$ \\
\hline
\end{tabular}

$A R T=$ Artesunate $A M Q=$ Amodiaquine, $C Q=$ Chloroquine, $M Q=$ Mefloquine 
rland (Lariam®), Phyto-Riker-GIHOC of Ghana (Amodiaquine and Chloroquine), Danpong-Adams Pharmaceuticals Ltd., of Ghana (Artesunate), Kinapharma Ltd., of Ghana (Malafan $^{\mathrm{TM}}$ and Amotex ${ }^{\circledR)}$ ) and Beijing Novartis Pharma Ltd., of China (Coartem $\left.{ }^{\circledR}\right)$. The Ghanaian public is able to access these medications over the counter for the management of uncomplicated malaria.

\section{DISCUSSION}

The parasitaemia prevalence rate among school children was high. Of the 812 two eligible pupils screened, about $59 \%$ of them had malaria parasites and over $60 \%$ of these pupils were mildly anaemic. These findings are consistent with results of studies conducted in school children of holo-endemic western Kenya, Cotonou in Benin, and Ouagadougou in Burkina Faso (Siâne et al., 2004; Muchiri and Magnussen, 2004; Wang et al., 2005). In malaria-endemic areas, asymptomatic cases result due to development of variant-specific immunity and explain the low-grade infection during extended periods without clinical symptoms (Staalsoe et al., 2004). In this study, parasite rates did not vary much by age.

The parasite prevalence was significantly higher during the wet season $(69 \%)$ than the dry season (43\%). This implies that even though malaria transmission occurred throughout the year, it showed marked seasonal influences. Over $5 \%$ of all chilren with parasites had gametocytes and were therefore cryptic carrier reservoirs for the communities (Osorio et al., 2004). The impact of repeated malarial episodes is thought to have detrimental effects on the development of the child, particularly his/ her mental and cognitive function (Fernando et al., 2003; Siâne et al., 2004). Although the school performance of a child depends on multiple factors, repeated absenteeism from school due to malaria significantly affects his/her performance (Sternberg et al., 2001 and 2002; Jukes, 2005).

A remarkable $60 \%$ of the asymptomatic chil- dren were anaemic on the screening day (Kurtzhals et al., 1999) however, 14\% of them had severe anaemia $(\mathrm{Hb}<8.0 \mathrm{~g} / \mathrm{dl})$. After pupils with malaria parasites were treated with ACTs, there were remarkable reductions of parasite prevalence by days 14 and 28 follow up and a corresponding increase in the mean $\mathrm{Hb}$ values. This suggests that the treatment and hence parsite clearance may have contributed to the rise in the post-treatment $\mathrm{Hb}$ concentrations. This is consistent with an improvement of $\mathrm{Hb}$ concentrations following treatment with ACTs (Koram et al., 2002).

Malaria is associated with anaemia (Ezzati et al., 2002; Ashton et al., 2011), and its insidious nature of presentation means that mild-tomoderate degrees of anaemia frequently remain undetected and untreated by health care workers and in the community (Phillips-Howard et al., 2003; Schellenberg et al., 2003). Studies have shown that long-term asymptomatic malaria could lead to anaemia (Gendrel et al., 1992). Other studies however, associate anaemia with other factors such as iron, folate and vitamin deficiencies, worm infestation, HIV/ AIDS and haemoglobinopathies (Lozoff et al., 2000; WHO/UNICEF, 2001). Thus, although malaria plays a key etiologic role in anaemia in endemic countries, it is clear that other factors make important additional contributions.

\section{CONCLUSIONS AND RECOMMENDA- TIONS}

Asymptomatic malaria parasitaemia with associated anaemia may be a burden in pre-school and primary school children in public schools of rural Ghana. Such infections are unlikely to be picked up or managed in populations where only those with clinical symptoms access diagnostic and treatment services; this may contribute to on-going transmission in these populations. It would be helpful to compare schoolbased malaria survey findings with those from standardized community-based surveys such as the Multi-indicator Cluster Survey (MICS) to determine whether school-based surveys could become an alternative to the more expensive 
community-based surveys. There is also the need to explore the relationship between school -absenteeism and malaria.

Not all ACTS will give the expected treatment outcomes related to improvement in $\mathrm{Hb}$ levels among school children. A well-designed school -based health programme for malaria can be a cost-effective public health intervention. It is recommended that more rigorous school-based studies are undertaken to confirm or otherwise, the need for investment in school-based malaria control interventions.

\section{Acknowledgements}

We are grateful to Dr. Badu Sarkodie, the Metropolitan Health Management Team and the Ejisu-Juaben Ghana Education Service Municipal Directorate for their assistance during the survey. We are thankful to all the mothers and caregivers for giving us their consent to enroll their children, and we gratefully acknowledge the school children who participated in the study.

\section{Conflict of interest}

We declare no conflict of interest.

\section{REFERENCES}

Ashton, R., Kefyalew, T., Tesfaye, G., Pullan, R. L., Yadeta, D., Reithinger R., Kolaczinski, J. H. and Brooker, S. (2011). School-based surveys of malaria in Oromia Regional State, Ethiopia: a rapid survey method for malaria in low transmission settings. Malaria Journal, 10:25. Available a $\mathrm{t} \quad \mathrm{h} \mathrm{t} \mathrm{t} \mathrm{p} \mathrm{:} \mathrm{w} \mathrm{w} \mathrm{w} \mathrm{m} \mathrm{a} 1$ a r i a journalcom.content/10/1/25. Accessed on 6 , 2011

Brooker, S., Kolaczinski, J., Gitonga, C., Noor, A., and Snow, R. (2009). The use of schools for malaria surveillance and programme evaluation in Africa. Malar J, 8:231

Browne, E. N. L., Frimpong, E., Sievertsen, J., Hagen, J., Hamelmann, C., Dietz, K., Horstmann, R. and Burchard, G. D. (2000).
Malariometric update for the rainforest and savannah of Ashanti region, Ghana. Annals of Tropical Medicine and Parasitology, 94 (1): 15-22.

Bundy, D. A. P., Lwin, S., Osika, J. S., McLaughlin, J. and Pannenborg, C. O. (2000). What should schools do about malaria? Parasitology Today, 16: 181-182.

Ezzati, M., Lopez, A. D., Rodgers, A., Vander, H. S. and Murray, C. J. (2002). The Comparative Risk Assessment Collaborating Group. Selected major risk factors and global and regional burden of disease. Lancet 360 , (9343):1347-60.

Fernando, S. D., Wickremasinghe, R., Mendis, K. N. and Wickremasinghe, A. R. (2003). Cognitive performance at school entry of children living in malaria-endemic areas of Sri Lanka. Transactions of the Royal Society of Tropical Medicine and Hygiene, 97 (2): 161-165.

Fernando, S. D., Gunawardena, D. M., Bandara, M., De Silva, D., Carter, R. and Mendis, K. N. (2003). The impact of repeated malaria attacks on the school performance of children. American Journal of Tropical Medicine and Hygiene, 69(6): 582-588.

Gendrel, D., Kombila, M., Nardou, M., Gendrel, C., Djouba, F., Martz, M. and RichardLenoble, D. (1992). Malaria and haemoglobin S: interactions in African children. Medical Press, 21:887-890.

Ghana Health Service-Ejisu-Juaben DHMT. (2003). Annual Report-2002. Ghana Health Service, Ejisu, Ashanti Region

Greenwood, B. M. (1987). Asymptomatic malaria infections: do they matter? Parasitology Today, 3: 206-214.

Holding, P. A., Peshu, N., Stevenson, J. and 
Marsh, K. (1999). Cognitive sequelae of severe malaria with impaired consciousness. Transactions of the Royal Society of Tropical Medicine and Hygiene, 93: 529-534.

Holding, P. A. and Snow, R. W. (2001). Impact of Plasmodium falciparum malaria on performance and learning: review of the evidence. American Journal of Tropical Medicine and Hygiene, 64 (Suppl): 68-75.

Jukes, M. (2005). The long-term impact of preschool health and nutrition on education. Food and Nutrition Bulletin, 26 (2) (supplement 2): S193-S201.

Koram, K. A., Owusu-Agyei, S., Utz, G., Binka, F. N., Baird, J. K., Hoffman, S. L. and Nkrumah, F. K. (2002). Severe anaemia in young children after high and low malaria transmission seasons in the KassenaNankana district of northern Ghana. American Journal of Tropical Medicine and Hygiene, 62:670-674.

Kurtzhals, J. A. L., Addae, M. M., Akanmori, B. D., Dunyo, S., Koram, K. A., Appawu, M. A., Nkrumah, F. K. and Hviid, L. (1999). Anaemia caused by asymptomatic Plasmodium falciparum infection in semi-immune African schoolchildren. Transactions of the Royal Society of Tropical Medicine and Hygiene, 93: 623-627.

Landry-Erik, M., Ntoumi, F., Bisseye, C., Ossari, S., Lu, C. Y., Nagel, R. I. and Krishnamoorthy, R. (2003). Human genetic polymorphisms and asymptomatic Plasmodium falciparum malaria in Gabonese schoolchildren. American Journal of Tropical Medicine and Hygiene, 68(2): 186-190

Lozoff, B., Jimenez, E., Hagen, J., Mollen, E. and Wolf, A. W. (2000). Poorer behavioral and developmental outcome more than 10 years after treatment for iron deficiency in infancy. Pediatrics, 105: E51.
Muchiri, E. and Magnussen, P. (2004). Malaria morbidity among school children living in two areas of contrasting transmission in Western Kenya. American Journal of Tropical Medicine and Hygiene, 71(6): 732-738.

Murphy, S. C., and Breman, J. G. (2001). Gaps in the childhood malaria burden in Africa: cerebral malaria, neurological sequelae, anaemia, respiratory distress, hypoglycemia, and complications of pregnancy. American Journal of Tropical Medicine and Hygiene, 64: 57-67.

Osorio, L., Todd, J., and Bradley, D. (2004). Absence of asymptomatic malaria in school children of Quibdo- Choco. Spanish Biomedical, 24(1):13-9.

Partnership for Child Development (1998). Cost of school-based drug treatment in Tanzania. Health Policy and Planning, 13(4): 384-396.

Phillips-Howard, P. A., Wannemuehler, K. A., ter Kuile, F. O., Hawley, W. A., Kolczak, M. S., Odhacha, A., Vulule, J. M. and Nahlen, B. L. (2003). Diagnostic and prescribing practices in peripheral health facilities in rural western Kenya. American Journal of Tropical Medicine and Hygiene, 68 (Suppl 4): 44-49.

Roll Back Malaria (2002). Briefing Document: Reducing Malaria's Impact on Child Health Development and Survival. World Health Organization. WHO/CD/RBM/2002.38

Siâne, C., Brooker, S., Kiambo, N. J., Njau, E., Estambale, B., Muchiri, E. and Magnussen, P. (2004). Malaria morbidity among school children living in two areas of contrasting transmission in Western Kenya American Journal of Tropical Medicine and Hygiene, 71(6): 732-738

Siâne, C., Brooker, S., Kiambo, N. J., Njau, E., Estambale, B., Staalsoe, T. and Hviid, L. 
(1998). The role of variant-specific immunity in asymptomatic malaria infections: maintaining a fine balance. Parasitology Today, 14: $177-178$.

Schellenberg, D., Schellenberg, J. R., Mushi, A., Savigny, D., Mgalula, L., Mbuya, C. and Victora, C. G. (2003). The silent burden of anaemia in Tanzanian children: a community -based study. Bulletin of the World Health Organization, 81: 581-590.

Snow, R. W., Craig, M., Deichmann, U. and Marsh, K. (1999). Estimating mortality, morbidity and disability due to malaria among Africa's non-pregnant population. Bulletin of World Health Organization, 77: 624-640.

Staalsoe, T., Shulman, C. E., Buhner, J. N., Kawuondo, K., Marsh, K. and Hviid, L. (2004). Variant surface antigen-specific IgG and protection against clinical consequences of pregnancy-associated Plasmodium falciparum malaria. Lancet, 363:283-289.

Sternberg, R. J., Nokes, K., Geissler, W., Prince, R., Okatcha, F., Bundy, D. A. P. and Grigorenko, E. L. (2001). The relationship between academic and practical intelligence: A case study in Kenya. Intelligence, 29 (5): 401-418.

Sternberg, R. J., Grigorenko, E. L., Ngorosho,
D., Tuntufye, E., Mbise, A., Nokes, C. A., Jukes, M. C. H. and Bundy, D. A. P. (2002). Assessing intellectual potential in rural Tanzanian school children. Intelligence, 30: 141162

United Nations Children's Fund (2004). A state of the world's children, New York

United Nations Children's Fund (2006).
Malaria and children: Progress in
intervention coverage: ITNs. UNICEF/RBM

Wang, S. J., Lengeler, C., Smith, T. A., Vounatsou, P. and Tanner, M. (2005). Rapid urban malaria appraisal (RUMA) final report for Cotonou. Roll Back Malaria Partnership, WHO, Basel 68.

World Health Organization (2003). The African Malaria Report. Geneva

WHO/UNICEF. (2001). Iron deficiency anaemia: Assessment, prevention and control. Geneva WHO (2000). Roll Back Malaria, WHO, Geneva.

World Health Organization (1997). Promoting health through schools: Report of a WHO Expert Committee on Comprehensive School Health Education and Promotion. WHO, Technical Report Series 870, Geneva. 